06

\title{
Формирование тонких графитовых пленок при диффузии углерода через никель
}

\author{
(C) Е.Г. Шустин, ${ }^{1,2}$ Н.В. Исаев, ${ }^{1}$ В.А. Лузанов, ${ }^{1}$ М.П. Темирязева ${ }^{1}$ \\ ${ }^{1}$ Институт радиотехники и электроники им. В.А. Котельникова РАН, Фрязинский филиал, \\ 141190 Фрязино, Московская обл., Россия \\ ${ }^{2}$ Национальный исследовательский ядерный университет МИФИ \\ e-mail: shustin@ms.ire.rssi.ru
}

(Поступило в Редакцию 25 июля 2016 г.)

\begin{abstract}
Представлены результаты опытов по синтезу тонких графитовых пленок методом отжига пленки никеля на углеродной подложке. В качестве подложки используется высоко ориентированный пиролитический графит, что обеспечивает хорошее структурное качество осажденной на него пленки никеля. Показано, что при циклическом отжиге этой структуры с промежуточным охлаждением происходит кристаллизация первичного аморфного углерода в пленку, состоящую из чешуек вертикального графена. Обсужден механизм процесса формирования графита.
\end{abstract}

DOI: 10.21883/JTF.2017.07.44677.2006

В последние годы графен вызывает большой интерес как функциональный материал для применения в электронике, солнечной энергетике, химических сенсорах и других разнообразных сферах деятельности благодаря его уникальным электрическим, оптическим, и механическим свойствам. Эти свойства и применения, как уже реализованные, так и потенциальные, детально и полно описаны в обзорах [1-4]. Хотя разработка методов получения графена идет широким фронтом [5], и в настоящее время достигнут значительный прогресс в получении пленок поликристаллического графена большой площади, а также монокристаллов структурно совершенного графена размерами до десятков микрон, критической проблемой остается контролируемый синтез однородных структурно совершенных монокристаллических пленок графена большой площади, пригодных для применения в наноэлектронике.

Наиболее широко используемый метод синтеза графена — крекинг углеводородов с осаждением продуктов атомов и радикалов углерода на подложку-катализатор (CVD-метод). В качестве таких подложек используются фольги или пленки переходных металлов - $\mathrm{Cu}, \mathrm{Ni}, \mathrm{Co}$, $\mathrm{Au}, \mathrm{Pt}$, Ir. Tребуемые для получения графена высокие температуры CVD-процесса, а также необходимость точной регулировки параметров (соотношения парциальных концентраций реагентов, длительности высокотемпературной стадии и периода остывания и др.) пока не позволили решить указанную выше задачу.

Среди подложек, используемых для синтеза графена, поверхность $\mathrm{Ni}(111)$ обеспечивает одну из лучших матриц из-за малого рассогласования решетки этой поверхности со структурой графена. Это свойство делает $\mathrm{Ni}(111)$ одним из самых многообещающих металловкатализаторов для эпитаксиального роста структурнооднородного графена. Однако существенная трудность в синтезе монослоя графена на $\mathrm{Ni}(111)$ связана с большой растворимостью углерода в никеле, приво- дящей к выделению графита значительной толщины при охлаждении подложки. Серьезной проблемой для получения однородной по толщине монокристаллической пленки является также двухдоменная структура гетероэпитаксиальной пленки $(111) \mathrm{Ni}$, домены которой развернуты друг относительно друга вокруг направления [111] на $180^{\circ}$. Согласно многочисленным литературным данным (см., например, [6-8]), для всех металлов с кубической гранецентрированной решеткой, которой обладает и никель, при их выращивании на подложках кубической симметрии характерно формирование гетероэпитаксиальных пленок двухдоменной структуры. Наличие границ между доменами микронных размеров приводит к большой концентрации центров зарождения графена, что ограничивает размеры зерен графена, значительно ухудшает электрические и механические свойства пленок графена и делает невозможным создание на их основе электронных устройств.

В работе [9] описана методика осаждения однодоменных гетероэпитаксиальных пленок никеля на сапфировых подложках. Показано, что высокотемпературный отжиг подложек в кислороде приводит к изменениям в приповерхностном слое, которые позволяют получить однодоменные гетероэпитаксиальные пленки (111) Ni на подложке (0001) $\mathrm{Al}_{2} \mathrm{O}_{3}$. Это может стать основой для разработки технологии изготовления монокристаллических графеновых слоев большой площади.

В $[10,11]$ было обнаружено, что углерод может диффундировать свозь пленку никеля и после охлаждения образовать графен между этой пленкой и подложкой. В последующем были опубликованы и другие работы, в которых графен получался при помощи диффузии углерода от твердого или газообразного источника через пленку металла-катализатора при ее отжиге. Наконец, в [12,13] сообщалось о синтезе монослойного графена на поверхности никеля, осажденного на высоко ориентированном пиролитическом графите (ВОПГ), диффузией 
атомов углерода через никель. Атомы углерода прибывают на поверхность $\mathrm{Ni}(111)$ (снизу) от углеродной подложки в отличие от метода крекинга, в котором атомы углерода адсорбируются из газообразной фазы (сверху). Высоко ориентированный пиролитический графит (ВОПГ) был выбран в качестве подложки, так как эпитаксия никеля на нем дает пленку-матрицу, наиболее близкую по структуре к требуемой для формирования графена. Особенно интересными представляются результаты работы [13], в которой формирование графена на никеле осуществлено при температурах $280-380^{\circ} \mathrm{C}$.

Как отмечается в [13], механизм синтеза графена при крекинге углеродсодержащего слоя на $\mathrm{Ni}(111)$ в литературе широко обсуждается и не имеет общепризнанной интерпретации. В наиболее широко принятой модели механизма предполагается, что формирование графитовой пленки происходит через каталитическое разложение молекул углеводородов на поверхности $\mathrm{Ni}(111)$ при температуре подложки свыше $500^{\circ} \mathrm{C}$ с одновременным растворением атомов углерода в объеме пленки никеля. Последующее снижение температуры подложки до комнатной температуры приводит к сегрегации и накоплению атомов углерода на поверхности (111) пленки $\mathrm{Ni}$ с кристаллизацией по матрице подложки (гетероэпитаксиальный синтез). Формирование монослойного углеродного покрытия, т.е. графена, с уменьшением температуры связано с ограниченной растворимостью атомов углерода в объеме пленки никеля. Другой механизм формирования монослойного графена на поверхности $\mathrm{Ni}(111)$ предполагает, что в приповерхностном слое образуется карбид никеля $\mathrm{Ni}_{2} \mathrm{C}$ с последующим его преобразованием в графен на поверхности никеля при определенных температурах $[13,14]$. Заметим, что в многих работах (см., например, [15]) образование карбида никеля при температурах ниже $480^{\circ} \mathrm{C}$ считается препятствием для формирования структуры графена на поверхности никеля.

Здесь мы сообщаем о нашем опыте получения наноразмерных пленок графита на пленке никеля, эпитаксиально осажденной на поверхность ВОПГ. Целью работы было исследование возможности получения однослойного или многослойного графена методом отжига в достаточно простых технологических условиях, представляющих перспективу для дальнейшего использования этих режимов в технологии получения графена непосредственно на диэлектрической (сапфировой) подложке.

Никель толщиной $60 \mathrm{~nm}$ наносился на пластины ВОПГ методом магнетронного напыления в вакууме при температуре подложки $360-380^{\circ} \mathrm{C}$, скорости роста пленки $2 \mathrm{~nm} / \mathrm{s}$. Выращенные гетероэпитаксиальные пленки $\mathrm{Ni}(111)$ имеют достаточно высокую степень совершенства кристаллической структуры (с полушириной кривой качания $<0.3)$.

Попытки получить пленку графита на никеле в широком диапазоне температур дали отрицательный результат: пленки никеля с толщиной 80-100 nm при нагреве до температуры выше $650^{\circ} \mathrm{C}$ в течение $3-5 \mathrm{~h}$ теряли

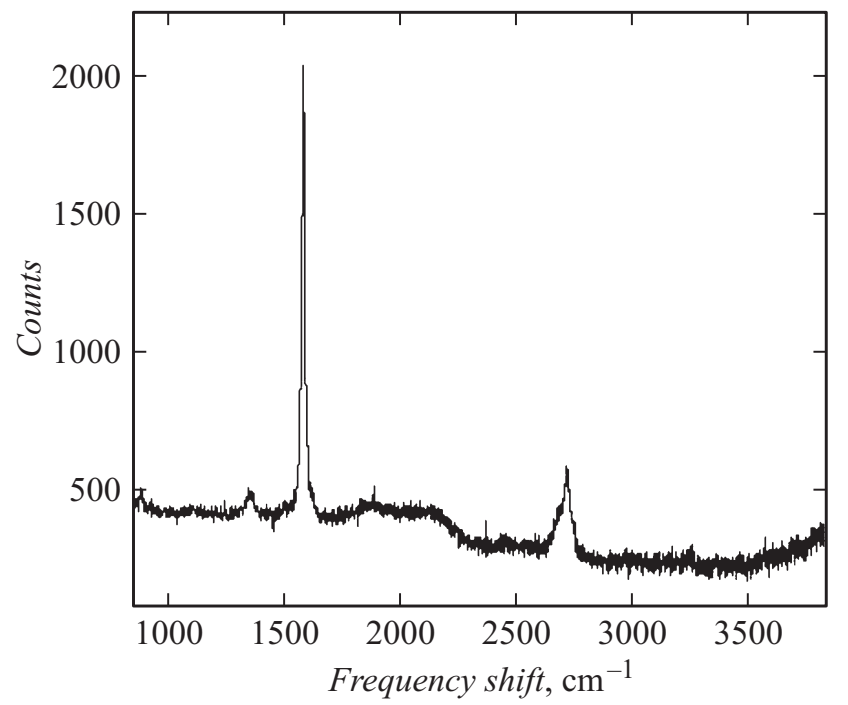

Рис. 1. Характерный раман-спектр пленки на поверхности структуры Ni/HOPG при толщине никелевой пленки $60 \mathrm{~nm}$ после отжига при $T=600^{\circ} \mathrm{C}$ в течение $6 \mathrm{~h}$.

сплошную структуру (коагулировали). Этот эффект не зависит от вида подложки, на которую осажден никель: тот же результат получается и при отжиге пленки никеля на атомно-гладкой поверхности сапфира $\left(\mathrm{Al}_{2} \mathrm{O}_{3}\right)$. Как показал анализ литературных данных [16], процесс коагуляции тонкой пленки в вакууме является неизбежным следствием гетерогенного характера процесса травления: плавление поверхности кристалла происходит при температуре, существенно меньшей температуры плавления объемного материала. В [16] наглядно показано, как это явление приводит к коагуляции тонких пленок на инертной поверхности. Мы убедились, что температура $600^{\circ} \mathrm{C}$ для пленок никеля толщиной $60 \mathrm{~nm}$ является предельной с точки зрения сохранения сплошной пленки.

В наших опытах процесс проводился при следующих условиях. После откачки вакуумной камеры до давления $(0.5-1) \cdot 10^{-2} \mathrm{~Pa}$ она заполнялась водородом до $10^{2} \mathrm{~Pa}$, и проводился кратковременный (15-20 min) отжиг образцов при температуре $400-500^{\circ} \mathrm{C}$ для восстановления естественно образующейся на поверхности никеля окисной пленки. Затем камера заполнялась аргоном при давлении 0.05-0.1 Ра с добавкой водорода (парциальное давление - $1 / 10$ давления аргона) и производился отжиг при указанной выше температуре, после чего осуществлялось охлаждение со скоростью $\sim 40^{\circ} \mathrm{C} / \mathrm{min}$ в той же атмосфере. Характеризация полученных пленок проводилась с помощью раман-микроспектрометра RamMics (производство OОО „ИнСпектр“, Черноголовка, Россия) и атомно-силового микроскопа SmartSPM (ООО „АИСТ“, Зеленоград, Россия).

Отжиг при этих температурах структуры с никелем в течение 4-6h приводил к формированию на поверхности никеля графитовой пленки. По соотношению 


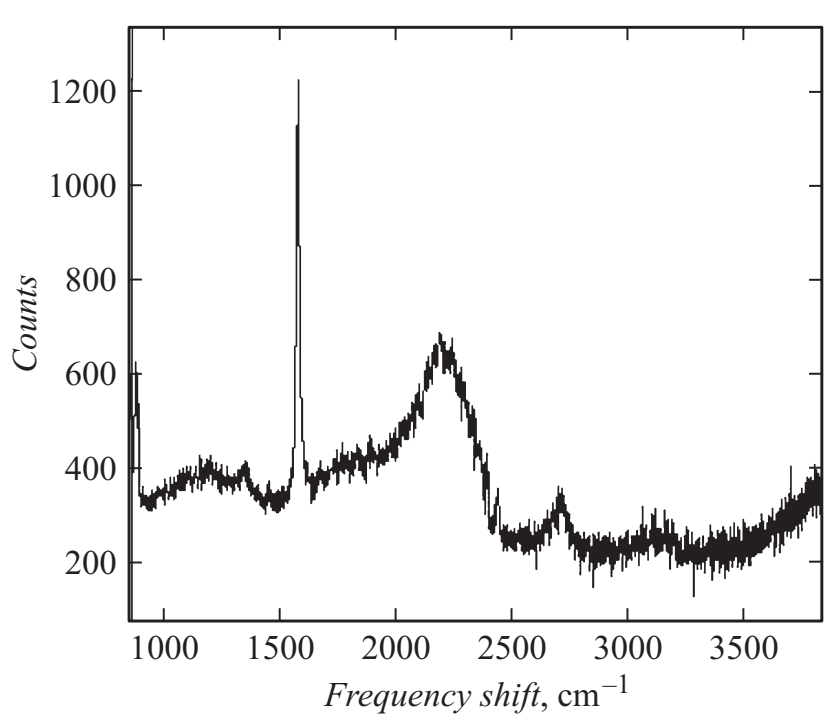

Рис. 2. То же - при толщине никеля $150 \mathrm{~nm}$.

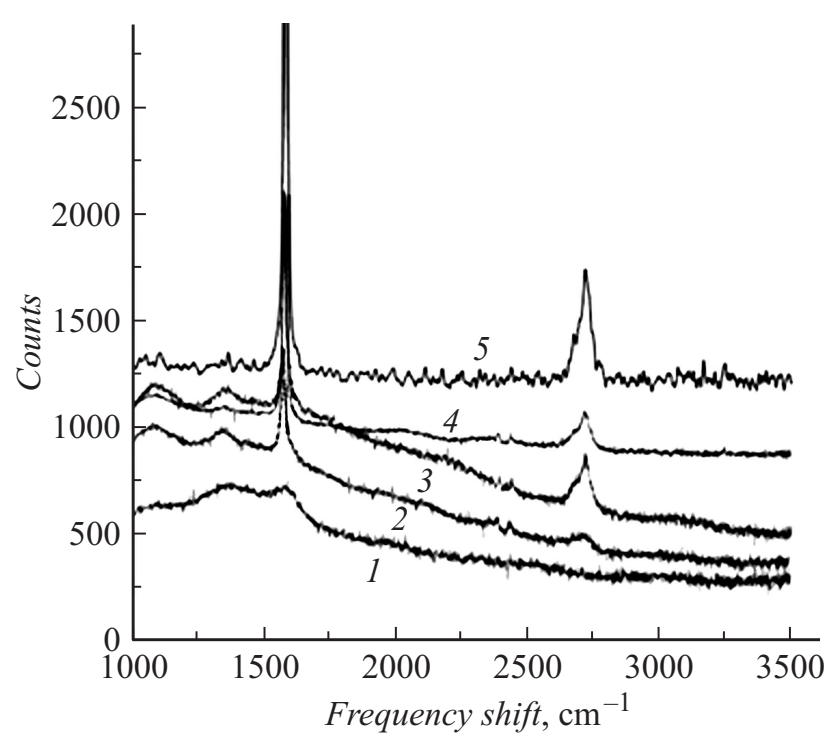

Рис. 3. Раман-спектры углеродной пленки на поверхности структуры Ni/HOPG после серии отжигов: 1 - первый отжиг при $T=600^{\circ} \mathrm{C} 2 \mathrm{~h}, 2-5-$ последовательные циклы при $T=500^{\circ} \mathrm{C}$, по $2 \mathrm{~h}$.

амплитуд пиков $2 D$ и $G$ и форме пика $2 D$ в спектре комбинационного рассеяния (КР) (рис. 1) можно видеть, что толщина пленки существенно превышает толщину атомного слоя. Можно было надеяться, что сокращение времени отжига приведет к уменьшению толщины пленки. Однако динамика процесса оказалась более сложной. При времени отжига до $15 \mathrm{~min}$ (при толщине никеля $60 \mathrm{~nm}$ ) раман-спектроскопия не обнаруживает следов углерода на поверхности никеля; при нагреве в течение $1 \mathrm{~h}$ регистрируется спектр аморфного углерода $(a-\mathrm{C})$, и при времени от 2 до $4 \mathrm{~h}-$ спектр представляет собой суперпозицию пиков графита и сплошного спектра, характерного для аморфного углерода (рис. 2).
Повторные отжиги образцов с пленкой аморфного углерода небольшой толщины при более низкой температуре, чем температура первичного отжига, приводят к преобразованию этой пленки в графит. На рис. 3 показаны раман-спектры образца с никелевой пленкой на пластине ВОПГ (мозаичность 0.7-1.4 $)$ при последовательном отжиге в атмосфере $\operatorname{Ar}(80 \%)+\mathrm{H}_{2}(20 \%)$, $p=50.03 \mathrm{~Pa}$ при температуре $500^{\circ} \mathrm{C}$. Здесь следует отметить, что серия последовательных отжигов проводилась при температуре, существенно меньшей той, при которой получалась графитовая пленка в работах [7-9].

Этот результат подтверждает сложившиеся сейчас представления [17] о механизме образования графена через диффузию углеродных атомов и кластеров по поверхности подложки и сцепления их в гексагональную кристаллическую решетку. Мы полагаем, что представленный здесь результат поможет определить режимы получения монокристаллической пленки непосредственно на диэлектрической подложке путем отжига структуры сапфир/гетероэпитаксиальный никель.

Анализ структуры полученных таким способом пленок с помощью атомно-силовой микроскопии показал, что пленки не являются атомно-гладкими (рис. 4): на их поверхности наблюдаются кристаллиты высотой от 7
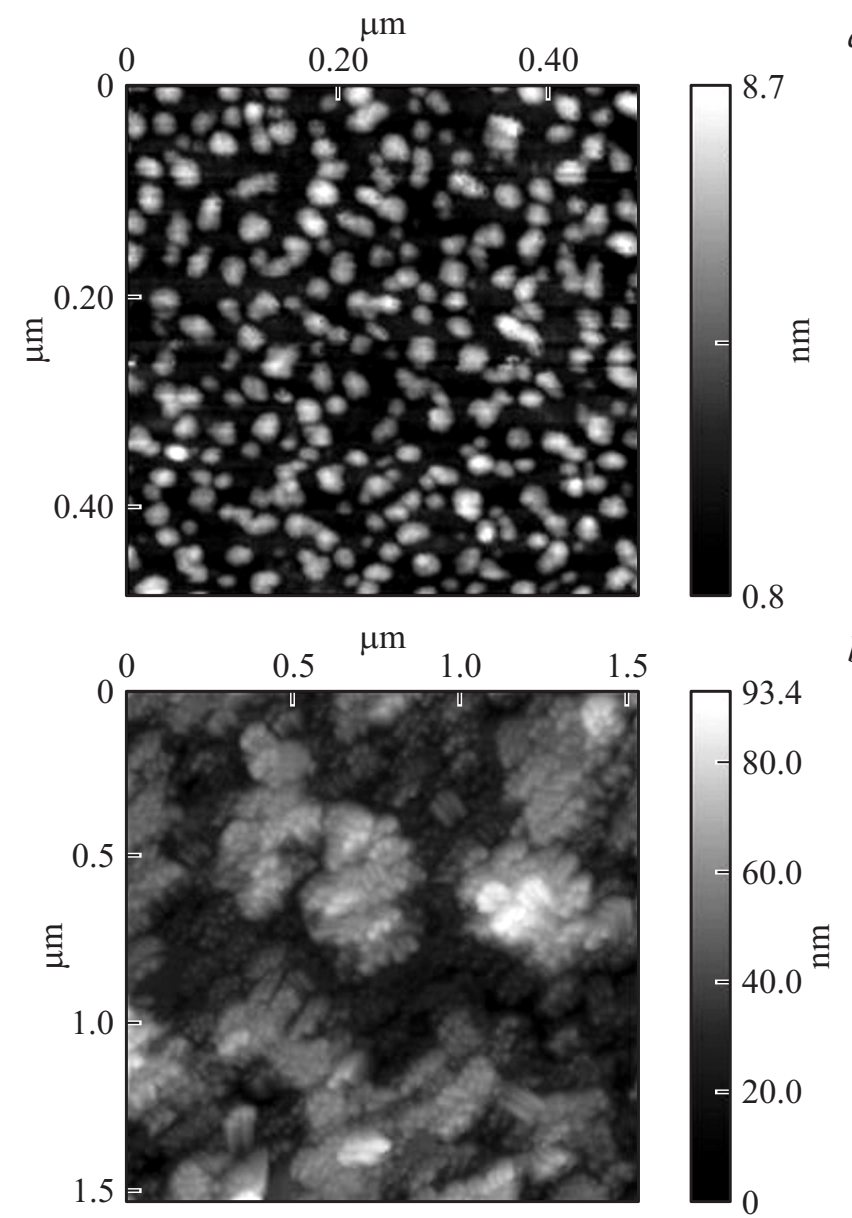

Рис. 4. АСМ-изображения двух образцов углеродной пленки на никеле. 
до $80 \mathrm{~nm}$ (в зависимости от условий первого отжига и толщины никелевой пленки). Можно предполагать, что этот эффект связан с преимущественным ростом графена на границах доменов никеля (напоминаем, что ВОПГ является текстурой, и осажденная на нее пленка никеля воспроизводит его морфологию).

Вертикально ориентированный графен вызывает растущий интерес для широкого круга приложений, от накопления энергии, катализа и автоэлектронной эмиссии до газовых сенсоров благодаря своим уникальной ориентации, острым кромкам, специфической морфологии и огромному отношению поверхности к объему $[18,19]$. Поэтому обнаруженный эффект роста вертикально растущих кристаллитов графена представляет самостоятельный интерес.

Работа выполнена при частичной поддержке РФФИ (грант № 14-08-00143) и Программы повышения конкурентоспособности НИЯУ МИФИ.

\section{Список литературы}

[1] Novoselov K.S., Fal'ko V.I., Colombo L. et al. // Nature. 2012. Vol. 490. P. 192-200.

[2] Randviir E.P., Brownson D.A.C., Banks C.E. // Mater. Today. 2014. Vol. 17. N 9. P. 426-432.

[3] Ferrari A.C., Bonaccorso F., Fal'ko V. et al. // Nanoscale. 2015. Vol. 7. P. 4598-4810.

[4] Schwierz F. // Nat. Nanotechnol. 2010. Vol. 5. P. 487-496.

[5] Bonaccorso F., Lombardo A., Hasan T. et al. // Mater. Today. 2012. Vol. 15. P. 564-589.

[6] Bialas H., Heneka K. // Vacuum. 1994. Vol. 45. N 1. P. 79-87.

[7] Ramanathant S., Clemenpsa B., Amen U. // Phil. Mag. A. 2001. Vol. 81. N 8. P. 2073-2094.

[8] Фомин А.В, Маликов И.В., Винниченко В.Ю. и др. // Поверхность. Рентгеновские, синхротронные и нейтронные исследования. 2008. № 2. С. 27-32.

[9] Лузанов В.А., Котелянский И.М., Шустин Е.Г. // Радиотехника и электроника. 2017. Т. 62. № 7.

[10] Sun Z., Yan J., Yao J. et al. // Nature. 2010. Vol. 468. P. 549 552.

[11] Peng Z., Yan Z., Sun Z., Tour J.M. // ACS Nano. 2011. Vol. 5. P. 8241-8247.

[12] Xu M., Fujita D., Sagisaka K., Watanabe E. // ACS Nano. 2011. Vol. 5. P. 1522-1528.

[13] Жижин Е.В., Пудиков Д.А., Рыбкин А.Г. и др. // ФТТ. 2015. Т. 57. Вып. 9. С. 1839-1845.

[14] Patera L.L., Africh C., Weatherup R.S., Blume R. et al. // ACS Nano. 2013. Vol. 7. P. 7901.

[15] Lahiri J., Miller T.S., Ross A.J. et al. // New J. Phys. 2011. Vol. 13. P. 025001.

[16] Громов Д.Г., Гаврилов С.А. // ФТТ. 2009. Т. 51. С. 2012 2021.

[17] Mohamed A.R. // Carbon. 2014. Vol. 70. P. 1-21.

[18] Bo Z., Yang Y., Chen J. et al. // Nanoscale. 2013. Vol. 5. P. 5180-5204.

[19] Bo Z., Mao S., Han Z.J. et al. // Chem. Soc. Rev. 2015. Vol. 44. P. 2108-2121. 